\section{Kidney Blood Pressure Research}

Kidney Blood Press Res 2018;43:1042-1052

\title{
Assessment of Peritoneal Membrane Arteriolar Structure in Conjunction with Traditional Cardiovascular System Evaluation in Chronic Kidney Disease (CKD) Stage 5 Patients
}

\author{
Rafał Donderskia Paweł Stróżeckia Beata Sulikowska ${ }^{a} \quad$ Magdalena Grajewska ${ }^{a}$ \\ Ryszard Trafny ${ }^{b}$ Magdalena Bodnarc, ${ }^{c, d}$ Andrzej Marszałek ${ }^{c}$ Anna Stefańska ${ }^{e}$ \\ Joanna Siódmiak ${ }^{\mathrm{e}}$ Grażyna Odrowąż-Sypniewska ${ }^{\mathrm{e}}$ Jacek Manitius ${ }^{\mathrm{a}}$ \\ aDepartment of Nephrology, Hypertension and Internal Medicine, Collegium Medicum, Bydgoszcz, \\ Nicolaus Copernicus University, Toruń; 'Braun-Avitum Dialysis Center, Golub-Dobrzyń, 'Department \\ of Clinical Pathology, Collegium Medicum, Nicolaus Copernicus University, Toruń, dDepartment of \\ Otolaryngology and Laryngeal Oncology, K. Marcinkowski University of Medical Sciences, Poznań, \\ eDepartment of Clinical Laboratory Medicine, Collegium Medicum, Nicolaus Copernicus University, \\ Toruń, Poland
}

\section{Key Words}

Chronic kidney disease - Peritoneal membrane - Arteriolar structure - Diabetic and nondiabetic population $\cdot$ ardiovascular complications

\begin{abstract}
Background/Aims: Cardiovascular complications are responsible for increased mortality and morbidity in chronic kidney disease (CKD) patients. Functional and structural changes of peritoneal membrane are reported in CKD patients both on conservative treatment and on renal replacement therapy (RRT). The aim of the study was to assess the structure of peritoneal membrane small arteries (precapillary arterioles) in diabetic and non-diabetic CKD stage 5 patients before initiation of peritoneal dialysis (PD) and evaluate its relationship with heart and large arteries abnormalities and with selected biochemical parameters. Methods: Evaluation of 42 CKD stage 5 patients before starting PD. Diabetic $(n=26)$ and non-diabetic $(n=16)$ patients were compared. Peritoneal membrane samples were taken during Tenckhoff catheter insertion. Histopathological evaluation of peritoneal precapillary arterioles (arteriolar evaluation) with measurement of wall thickness (WT) and calculation of lumen/vessel (L/V) ratio was performed in each patients. Echocardiography, intima media thickness (IMT), pulse wave velocity (PWV), ambulatory blood pressure monitoring (ABPM) and biochemical parameters
\end{abstract}




\section{Kidney Blood Pressure Research}

Kidney Blood Press Res 2018;43:1042-1052

\begin{tabular}{l|l}
\hline DOI: $10.1159 / 000490827$ & (C) 2018 The Author(s). Published by S. Karger AG, Base
\end{tabular}

Published online: 25 June, 2018

www.karger.com/kb

assessment: serum albumin $(\mathrm{SA})$, total cholesterol $(\mathrm{TCH})$, hemoglobin $(\mathrm{Hgb})$, parathormone $(\mathrm{PTH})$, serum calcium $(\mathrm{Ca})$, serum phosphorus $(\mathrm{P})$, transferrin saturation (TSAT\%), C-reactive protein (CRP) were performed in each participant. Results: There were no statistically significant differences in peritoneal membrane arteriolar indices - wall thickness (WT) and L/V ratio between investigated groups. There was statistically significant higher PWV value in diabetic patients. There were no statistically significant differences in echocardiographic indices, IMT, laboratory data in analyzed groups. There were some linear correlations between: PWV vs IMT $(R=0,84 ; p=0,0006) ; P W V$ vs PP $(R=0,58 ; p=0,03)$ in non-diabetic and linear correlation between: PWV vs age $(R=0,75 ; p=0,02)$; WT vs $\triangle P(R=-0,93 ; p=0,001)$; WT vs $D B P(R=0,64$; $p=0,04)$ in diabetic group. Conclusion: Peritoneal membrane arteriolar damage seems to be an integrated part of cardiovascular system damage in CKD stage 5 patients.

(C) 2018 The Author(s)

Published by S. Karger AG, Basel

\section{Introduction}

Cardiovascular disease (CVD) is overexpressed in chronic kidney disease (CKD) patients. The risk of CVD increases with kidney function decline. Atherosclerotic CVD accounts for more than half of death in CKD patients and cardiovascular mortality is 10 to 30 fold higher than that seen in general population. Cardiovascular complications related with accelerated atherosclerosis are observed even in young patients [1-3]. The high CVD risk in CKD is associated with well -known traditional and non-traditional risk factors $[4,5]$. The peritoneal microcirculation is an intricate network which connect systemic vasculature and the peritoneal cavity. Many former studies were focused on heart and large arteries assessment but the data concerning peritoneal small vessels disease in CKD are sparse. Metabolic disturbances related to CKD, long lasting hypertension and diabetes mellitus are responsible for functional and structural damage of this microcirculation. The consequences of these processes is premature and aggressive atherosclerosis and reduced capillary density which also affects peritoneal microcirculation [6, 7]. Moreover, it is well documented that bioincompatible fluids used in long-term peritoneal dialysis (PD) treatment, peritonitis episodes, may also impact on peritoneal membrane (PM) function and structure. PM changes such as: interstitial fibrosis (thickening of submesothelial interstitial layer) and hyalinizing vasculopathy may be initiated in predialysis pts and may aggravate during PD treatment [8-11]. There are few methods of assessment of PM microcirculation such as: microvascular density evaluation, analysis of angiogenesis-regulating proteins expression - vascular endothelial growth factor (VEGF), vascular endothelial growth factor receptor (VEGFR), angiopoietin 1 (Angpt1), angiopoietin2 (Angpt2). Histologic evaluation of PM morphology with average peritoneal thickness and peritoneal arteriolar structure assessment is another precious method. We hypothesize that functional and structural changes of peritoneal membrane arteriolar structure in CKD patients are initiated at early stages of disease and progress with renal function decline. Moreover, we assume that changes in peritoneal arteriolar proceed or are parallel to large vessels changes. The aim of the study was to evaluate peritoneal membrane arteriolar structure and to establish any relationships between arteriolar parameters, heart structure, large arteries parameters (evaluated using non-invasive methods) and laboratory parameters in CKD stage 5 patients.

\section{Materials and Methods}

42 Caucasian patients (pts) entered the study. There were: $19 \mathrm{~F}$ and $23 \mathrm{M}$ (mean age 51.3 \pm 17.1 ). All pts were at stage 5 of CKD before initiating peritoneal dialysis as a first option of RRT. There was no need to start urgent hemodialysis. The pts were recruited from Outpatient Clinic of Department of Nephrology, Hypertension and Internal Medicine at Ludwik Rydygier University Hospital in Bydgoszcz and one local Nephrology Outpatient Clinic located in our region. The causes of CKD were: diabetic kidney disease - 


\section{Kidney Blood Pressure Research}

Kidney Blood Press Res 2018;43:1042-1052

\begin{tabular}{l|l}
\hline DOI: $10.1159 / 000490827$ & (C) 2018 The Author(s). Published by S. Karger AG, Basel
\end{tabular}

Published online: 25 June, 2018 www.karger.com/kbr

26pts (typ 1- 9pts /typ2 - 17pts), chronic glomerulonephritis (CGN) confirmed by renal biopsy - 7pts; tubulointerstitial nephropathy- 4pts, obstructive nephropathy - 3pts; hypertensive nephropathy $2 \mathrm{pt}$; In further analysis patients were divided into 2 groups: diabetic (26pts) and non-diabetic (16 pts). Inclusion criteria were: age $>18 y e a r s$ old; stable clinical condition 4 weeks prior to enrolment, no signs of inflammation ( $\mathrm{CRP}<5,0 \mathrm{mg} / \mathrm{L})$, written informed consent, $\mathrm{PD}$ as a first option of RRT. Exclusion criteria were: active immunosuppressive therapy. Comorbid conditions at the onset of the study were: coronary artery disease (CAD) diagnosed in 15 pts, hypertension-28pts, symptoms of congestive heart failure (CHF) were present in 9pts; 1 patients was after transient ischemic attack (TIA) incident. The patients who suffered from hypertension, required 2 or more antihypertensive agents. Treatment of hypertension was in accordance with current guidelines of ESH/ESC. The goal of treatment was to reach blood pressure below $<140 / 90 \mathrm{mmHg}$. The following medications were prescribed: angiotensin converting enzyme inhibitors (ACE-Is) - 35 pts, angiotensin receptor blockers (ARBs) - 7pts, calcium channel blockers - 27; $\beta$-blockers - 15pts, loop diuretics - 42 pts. Patients who reached end-stage kidney disease and there was eGFR $<20 \mathrm{ml} / \mathrm{min}$ according to CKD-EPI formula in diabetic kidney disease and eGFR $<15 \mathrm{ml} / \mathrm{min}$ in nondiabetic cases were offered PD as a first renal replacement therapy option. 3-4 weeks after Tenckhoff catheter insertion, patients started continuous ambulatory peritoneal dialysis (CAPD) than, 2 months later they were transferred to conventional automated peritoneal dialysis (APD) delivered by Baxter (USA). Renal anemia was treated using darbepoetin-alfa subcutaneously according to KDIGO Clinical Practice Guidelines to reach hemoglobin level between $10,0 \mathrm{~g} / \mathrm{dl}$ to $11,5 \mathrm{~g} / \mathrm{dl}$. Chronic kidney disease - mineral and bone disorder (CKD-MBD) were treated according to KDIGO guidelines 2016 (Uptade on the management of CKD-MBD) using conventional therapy: vitamin D (alfacalcidol daily in a dose from $0,25 \mu \mathrm{g}$ to $0,5 \mu \mathrm{g}$ daily) and calcium-phosphorus binders (calcium carbonate in a dose from 3, 0g daily to $6,0 \mathrm{~g}$ daily) and noncalcium phosphorus binder (sevelamer hydrochloride in a dose: 3 x 0 , 8g daily).

\section{Evaluation of small arteries of peritoneal membrane}

To assess structure of peritoneal small arteries (peritoneal arterioles) peritoneal membrane specimens (from parietal peritoneum) at least $3 \mathrm{~cm}$ width, were taken during Tenckhoff catheter insertion. They were immediately fixed in $10 \%$ buffered formalin solution. Following the standard procedure, tissue samples were processed and embedded in paraffin blocks, and then cut into 3-4 $\mu \mathrm{m}$ slides and stained with hematoxylin and eosin. Peritoneal arterioles were analyzed after the standardized immunohistochemical procedure using anti-CD31 antibodies. The visual analysis of the peritoneal arteries was performed using the Imaging System NIS ELEMENTS AR. Part of that system was light microscopy connected with computer. Each histologic sample were evaluated with magnification 40x. 5 arteries obtained from each patient were evaluated. Thickness of vascular wall (assessed in 5 separate points), luminal diameter and external arteriolar diameter were measured in each patient. Results were expressed in micrometers $(\mu \mathrm{m})$. Thanks to luminal diameter and external arteriolar diameter measurements, ratio of luminal diameter to whole arteriolar diameter $(\mathrm{L} / \mathrm{V})$ were calculated in each individual. These values reflected the patency of vessels. Lowering of $\mathrm{L} / \mathrm{V}$ ratio is an indicator of arteriolar narrowing. All histopathological images were evaluated by 2 investigators i.e. nephrologist and experienced pathologist. Precapillary arterioles with external diameter range $25-75 \mu \mathrm{m}$ selected by experienced pathologist were chosen for detailed measurements. The distance was measured in one short axis of the vessel. The concept of these measurements is presented in Fig.1.

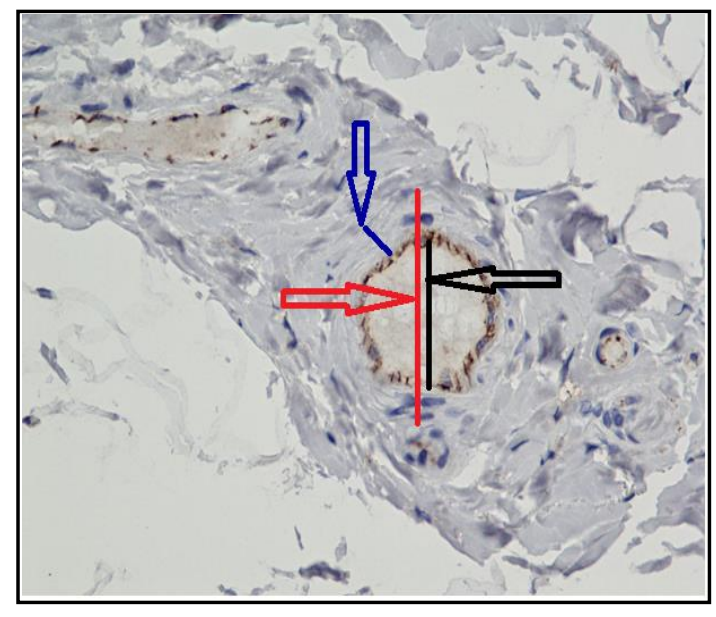

Fig. 1. The concept of the arteriolar measurements performed in the study. The CD-31 antibody staining method was used to identify arteriolar structure. Red arrow - measurement of external arteriolar diameter. Black arrow - measurement of internal arteriolar diameter (lumen). Blue arrow measurement of arteriolar wall thickness. 


\section{Kidney Blood Pressure Research}

Kidney Blood Press Res 2018;43:1042-1052

\begin{tabular}{l|l}
\hline DOI: $10.1159 / 000490827$ & (C) 2018 The Author(s). Published by S. Karger AG, Basel
\end{tabular}

Published online: 25 June, 2018

www.karger.com/kbr

\section{Evaluation of heart structure and large arteries}

Pulse wave velocity measurements. Carotid-femoral PWV was measured using the Complior $\AA$ device (Artech Medical, Pantin, France). Two transducers - one positioned over the carotid artery and second over the femoral artery - were used to measure the time delay between pulse waves. Time delay was measured on 10 successive beats, and then averaged. The distance between the carotid artery (suprasternal notch) and the femoral artery was measured externally. PWV was calculated according to the formula: PWV = distance $(\mathrm{m})$ / time delay (s). PWV measurements were taken in duplicate and averaged.

\section{Intima-media thickness measurements}

Common carotid arteries were examined in all patients, in the supine position after a 5-minute rest, with high resolution real-time ultrasonography using an $11 \mathrm{MHz}$ linear probe. Measurements were performed on frozen mode images. Intima-media thickness (IMT) was measured 10-30 mm proximally to the carotid bifurcation, on the carotid far wall, in three points, free of atherosclerotic plaques. Measurements were done on both common carotid arteries and the results were averaged.

Echocardiography. Echocardiographic examination was performed in each patients at the beginning of the study. The measurements of intraventricular septum thickness in end-diastole (IVSd), left ventricular internal dimension in end-diastole (LVIDd), posterior wall in end-diastole (PWd) were performed. Left ventricular mass (LVM), left ventricular mass index, ejection fraction (EF) and left ventricle relative wall thickness (RWT) were calculated. The measurements were performed in accordance with latest guidelines given by the American Society of Echocardiography. Left ventricular systolic function impairment was defined as $\mathrm{EF}<55 \%$. Left ventricular hypertrophy (LVH) was defined as $\mathrm{LVMI}>95 \mathrm{~g} / \mathrm{m}^{2}$ for women and LVMI $>115 \mathrm{~g} / \mathrm{m}^{2}$ for men.

Ambulatory blood pressure monitoring (ABPM). 24 hours ambulatory blood pressure monitoring (ABPM) using A\&D TM 2430 device (Japan), was performed in each patient at the onset of the study. Mean values of systolic blood pressure (SBP), diastolic blood pressure (DBP), mean arterial pressure (MAP), and pulse pressure (PP) were analyzed.

Biochemical evaluation. Assessment of serum albumin (SA), C-reactive protein (CRP), hemoglobin (Hgb), total cholesterol (TCH), serum calcium (Ca), serum phosphorus (P), PTH, transferrin saturation (TSAT\%) were performed at the beginning of the study.

\section{Statistical analysis}

Statistical analysis was performed using the Statistica 7.0 PL software (StatSoft Inc., Tulsa, OK, USA). The obtained data are presented as mean \pm standard deviation (SD) and the median and top and bottom quartiles are given for variables that were not normally distributed. Distribution of variables was analyzed using the Shapiro-Wilk test. Statistical analysis was performed using the Student's t-test. If any variable was not normally distributed, the U Mann-Whitney test was used. Qualitative data were compared by means of the $\chi^{2}$ - test. Linear correlation between variables was analyzed using: Spearman rank correlation coefficient (for samples with non-normal distribution) and Pearson's correlation coefficient ( for samples with normal distribution) also. P value $<0,05$ was considered as statistically significant.

\section{Ethical approval}

The study protocol was approved by the local Bioethics Committee of Nicolaus Copernicus University in Toruń. Informed consent was obtained from all patients included in the study.

\section{Results}

Clinical characteristics of the patients is given in Table 1.

Comparison of cardiovascular system indices and morphometric analysis of peritoneal membrane arteriolar structure in diabetic and non-diabetic CKD group are presented in Table 2.

There were not any statistically significant differences in the most investigated parameters except PWV. 


\section{Kidney \\ Blood Pressure Research}

\begin{tabular}{l|l}
\hline Kidney Blood Press Res 2018;43:1042-1052 \\
\hline DOI: 10.1159/000490827 & $\begin{array}{l}\text { (c) } 2018 \text { The Author(s). Published by S. Karger AG, Basel } \\
\text { www.karger.com/kbr }\end{array}$ \\
$\begin{array}{ll}\text { Published online: 25 June, } 2018 & \end{array}$
\end{tabular}

Donderski et al.: Morphological Analysis of Peritoneal Membrane Arteriolar Structure in

Chronic Kidney Disease Stage 5 Patients

Table 1. Clinical characteristics of the patients at the onset of the study. Normally distributed data are expressed as mean \pm SD and not normally distributed data are expressed as median \pm IQR. Abbreviations: BMI - body mass index; WHR - waist hip ratio; SBP -systolic blood pressure; DBP -diastolic blood pressure; PP-pulse pressure; MAP - mean arterial pressure; eGFR - estimated glomerular filtration rate according to CKD-EPI equation; Hgb- hemoglobin, SA - serum albumin, CRP- C reactive protein; TCH- total cholesterol; TSAT - transferrin saturation; PTH - parathormone

\begin{tabular}{lccc}
\hline Parameter & $\begin{array}{c}\text { Non-diabetic patients } \\
(\mathrm{n}=16)\end{array}$ & $\begin{array}{c}\text { Diabetic patients } \\
(\mathrm{n}=26)\end{array}$ & $\mathrm{p}$ \\
\hline Age (years) & $48,4 \pm 20,4$ & $55,0 \pm 11,47$ & 0,20 \\
BMI(kg/m²) & $24,5 \pm 4,5$ & $25,2 \pm 4,1$ & 0,70 \\
WHR(cm) & $0,89 \pm 0,08$ & $0,92 \pm 0,09$ & 0,40 \\
BSA (m²) & $1,81 \pm 0,24$ & $1,84 \pm 0,15$ & 0,70 \\
SBP(mmHg) & $141,4 \pm 25,64$ & $152,7 \pm 18,54$ & 0,25 \\
PP (mmHg) & $55,07 \pm 17,46$ & $66,80 \pm 17,05$ & 0,12 \\
MAP (mmHg) & $104,74 \pm 16,50$ & $108,16 \pm 15,80$ & 0,62 \\
Serum creatinine (mg/dl) & $5,17 \pm 0,69$ & $4,32 \pm 0,39$ & 0,001 \\
eGFR (ml/min/1,73m $\left.{ }^{2}\right)$ & $9,5 \pm 1,78$ & $11,09 \pm 1,70$ & 0,03 \\
Hgb (g/dl) & $11,15 \pm 1,28$ & $10,25 \pm 1,23$ & 0,85 \\
SA (g/dl) & $3,95 \pm 0,54$ & $3,81 \pm 0,38$ & 0,48 \\
TCH (mg/dl) & $202,23 \pm 25,82$ & $200,50 \pm 42,97$ & 0,90 \\
CRP (mg/L) & $0,90 \pm 0,00$ & $2,74 \pm 2,13$ & 0,47 \\
TSAT (\%) & $24,66 \pm 7,86$ & $22,42 \pm 4,07$ & 0,42 \\
Calcium (mmol/l) & $2,16 \pm 0,21$ & 0,30 \\
Phosphorus (mmol/l) & $2,12 \pm 1,01$ & $2,24 \pm 0,13$ & 0,16 \\
PTH (pg/ml) & $306(137-570)$ & $1,64 \pm 0,30$ & 0,12 \\
\hline
\end{tabular}

Table 2. Peritoneal arteriolar structure analysis and cardiovascular system assessment in investigated population of CKD stage 5 patients. Normally distributed data are expressed as mean \pm SD and not normally distributed data are expressed as median \pm IQR. Abbreviations: IVSd - intraventricular septum thickness in end-diastole; LVIDd - left ventricular internal dimension in end- diastole; PWd- posterior wall in end diastole; EF - ejection fraction; LVM- left ventricular mass; RWT - left ventricule relative wall thickness; LVMI - left ventricular mass index; c-IMT -carotid intima-media thickness; PWV -pulse wave velocity; WT - wall thickness; L/V- peritoneal vessel lumen/ peritoneal vessel diameter ratio. Italic values denote statistical significant $(\mathrm{p}<0,05)$

\begin{tabular}{lccc}
\hline Parameter & $\begin{array}{c}\text { Non-diabetic patients } \\
(\mathrm{n}=16)\end{array}$ & $\begin{array}{c}\text { Diabetic patients } \\
(\mathrm{n}=26)\end{array}$ & $\mathrm{p}$ \\
\hline IVSd $(\mathrm{cm})$ & $1,25(1,0-1,6)$ & $1,1(0,9-1,6)$ & 0,50 \\
LVIDd $(\mathrm{cm})$ & $4,80(4,2-5,4)$ & $4,90(4,2-5,1)$ & 0,92 \\
PWd $(\mathrm{cm})$ & $1,15(0,90-1,50)$ & $1,0(0,90-1,50$ & 0,70 \\
RWT $(\mathrm{cm})$ & $0,46 \pm 0,08$ & $0,48 \pm 0,10$ & 0,63 \\
EF $(\%)$ & $64,05 \pm 5,67$ & $60,73 \pm 9,27$ & 0,30 \\
LVM $(\mathrm{g})$ & $218,13 \pm 77,95$ & $220,66 \pm 50,42$ & 0,92 \\
LVMI $\left(\mathrm{g} / \mathrm{m}^{2}\right)$ & $119,51 \pm 38,25$ & $118,58 \pm 21,19$ & 0,94 \\
c-IMT $(\mathrm{mm})$ & $0,65 \pm 0,16$ & $0,78 \pm 0,21$ & 0,11 \\
PWV $(\mathrm{m} / \mathrm{s})$ & $10,12 \pm 2,94$ & $14,83 \pm 3,57$ & 0,0029 \\
WT $(\mu \mathrm{m})$ & $9,19 \pm 3,24$ & $10,01 \pm 2,00$ & 0,92 \\
L/V ratio & $0,61 \pm 0,92$ & $0,58 \pm 0,87$ & 0,74 \\
\hline
\end{tabular}

PWV value was statistically significantly higher in diabetic kidney disease pts in compare to non-diabetic pts.

In non-diabetic CKD pts some statistically significant linear correlation were found (Table 3). There were linear correlation between $P W V$ vs $P P(R=0,58 ; p=0,03) ; P W V$ vs BSA $(\mathrm{R}=0,59 ; \mathrm{p}=0,03)$; $\mathrm{PWV}$ vs $\Delta \mathrm{Hgb}(\mathrm{R}=0,63 ; \mathrm{p}=0,02)$; IMT vs age $(\mathrm{R}=0,79 ; \mathrm{p}=0,002)$; IMT vs BSA ( $R=0,86 ; \mathrm{p}=0,003)$; IMT vs BMI $(\mathrm{R}=0,70 ; \mathrm{p}=0,01)$; WT vs $\Delta \mathrm{P}(\mathrm{R}=-0,62 ; \mathrm{p}=0,02)$; WT vs $\triangle \mathrm{Hb}(\mathrm{R}=-0,54 ; \mathrm{p}=0,05)$. Moreover, in diabetic CKD pts there were statistically significant correlation between: PWV vs age $(R=0,75 ; p=0,02)$; IMT vs $B S A(R=0,76 ; p=0,01)$; WT vs $\Delta \mathrm{P}(\mathrm{R}=-0,93 ; \mathrm{p}=0,001) ; \mathrm{WT}$ vs $\mathrm{DBP}(\mathrm{R}=0,64 ; \mathrm{p}=0,04) ; \mathrm{PWV}$ vs IMT $(\mathrm{R}=0,80 ; \mathrm{p}=0,002)$. 


\section{Kidney Blood Pressure Research}

Donderski et al.: Morphological Analysis of Peritoneal Membrane Arteriolar Structure in

Chronic Kidney Disease Stage 5 Patients

We performed analysis of arteriolar indices in subpopulations of patients with and without cardiovascular disease (CVD) (i.e CAD and CHF). Date are presented in Table 4 and Table 5.

The linear correlation between arteriolar indices and c-IMT are presented. (Fig. 2 and Fig. 3).

We do not have any drop outs during the study because of patient sudden death. There was 1 incident of NSTEMI in diabetic patient.

Table 3. Some statistically significant linear correlation between analyzed parameters in nondiabetic and diabetic group. Abbreviations: *means -only diabetic population; R- Spearman rank coefficient

Table 4. Peritoneal membrane arteriolar indices in population with and without CAD. Abbreviations: CAD 0 - without coronary artery disease ; CAD 1 - coronary artery disease presence; WT - wall thickness; L/V- peritoneal vessel lumen/ peritoneal vessel diameter ratio. Italic values denote statistical significant $(\mathrm{p}<0,05)$

Table 5. Peritoneal membrane arteriolar indices in population with and without CHF. Abbreviations: CHF 0 - without congestive heart failure ; CAD 1 - congestive heart failure presence; WT - wall thickness; L/V- peritoneal vessel lumen/ peritoneal vessel diameter ratio. Italic values denote statistical significant $(\mathrm{p}<0,05)$

Fig. 2. Linear correlation between c-IMT and WT in population with CVD.

\begin{tabular}{|c|c|c|c|c|c|}
\hline Parameter & \multicolumn{3}{|c|}{ PWV } & \multicolumn{2}{|c|}{ c-IMT } \\
\hline $\mathrm{PP}$ & \multicolumn{3}{|c|}{$\mathrm{R}=0,58 ; \mathrm{p}=0,03$} & \multicolumn{2}{|c|}{-} \\
\hline BSA & \multicolumn{3}{|c|}{$\mathrm{R}=0,59 ; \mathrm{p}=0,03$} & \multicolumn{2}{|c|}{$\mathrm{R}=0,86 ; \mathrm{p}=0,003$} \\
\hline BMI & \multicolumn{3}{|c|}{-} & \multicolumn{2}{|c|}{$\mathrm{R}=0,70 ; \mathrm{p}=0,01$} \\
\hline c-IMT & \multicolumn{3}{|c|}{$\mathrm{R}=0,80 ; \mathrm{p}=0,002$} & \multicolumn{2}{|c|}{-} \\
\hline$\Delta \mathrm{Hgb}$ & \multicolumn{3}{|c|}{$\mathrm{R}=0,63 ; \mathrm{p}=0,02$} & \multicolumn{2}{|c|}{ - } \\
\hline Age & \multicolumn{3}{|c|}{$* \mathrm{R}=0,75 ; \mathrm{p}=0,02$} & \multicolumn{2}{|c|}{$\mathrm{R}=0,79 ; \mathrm{p}=0,002$} \\
\hline \multirow{2}{*}{ Parameter } & \multicolumn{2}{|c|}{ CAD $0(N=27)$} & \multicolumn{2}{|c|}{ CAD $1(\mathrm{~N}=15)$} & \\
\hline & Mean & SD & Mean & SD & $\mathrm{p}$ \\
\hline$\overline{\mathrm{WT}}(\mu \mathrm{m})$ & 10,15 & 2,64 & 9,82 & 2,96 & 0,7881 \\
\hline $\mathrm{L} / \mathrm{V}$ ratio & 0,60 & 0,09 & 0,61 & 0,10 & 0,8751 \\
\hline
\end{tabular}

\begin{tabular}{lccccc}
\hline \multirow{2}{*}{ Parameter } & \multicolumn{2}{c}{ CHF 0 (N=33) } & \multicolumn{2}{c}{ CHF 1 (N=9) } & p \\
& Mean & SD & Mean & SD & \\
\hline WT $(\mu \mathrm{m})$ & 10,56 & 3,29 & 9,15 & 1,79 & 0,2374 \\
L/V ratio & 0,57 & 0,10 & 0,65 & 0,07 & 0,0472 \\
\hline
\end{tabular}

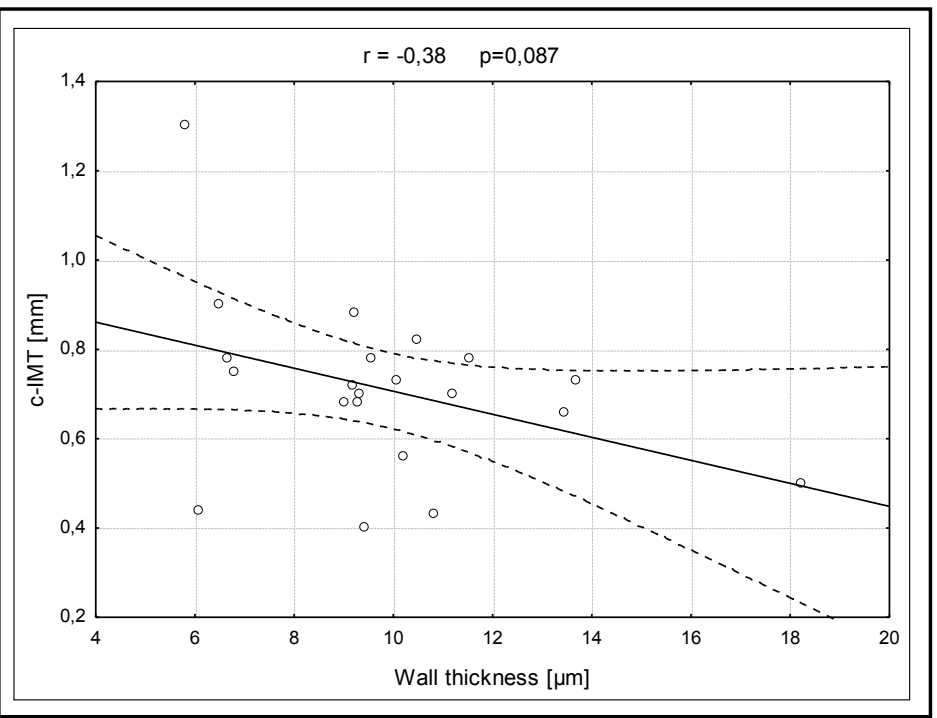




\section{Kidney \\ Blood Pressure Research}

Kidney Blood Press Res 2018;43:1042-1052

\begin{tabular}{l|l}
\hline DOI: $10.1159 / 000490827$ & (C) 2018 The Author(s). Published by S. Karger AG, Basel
\end{tabular}

Published online: 25 June, 2018

www.karger.com/kb

1048

Fig. 3. Linear correlation between c-IMT and L/V ratio in population with CVD.

Donderski et al.: Morphological Analysis of Peritoneal Membrane Arteriolar Structure in Chronic Kidney Disease Stage 5 Patients

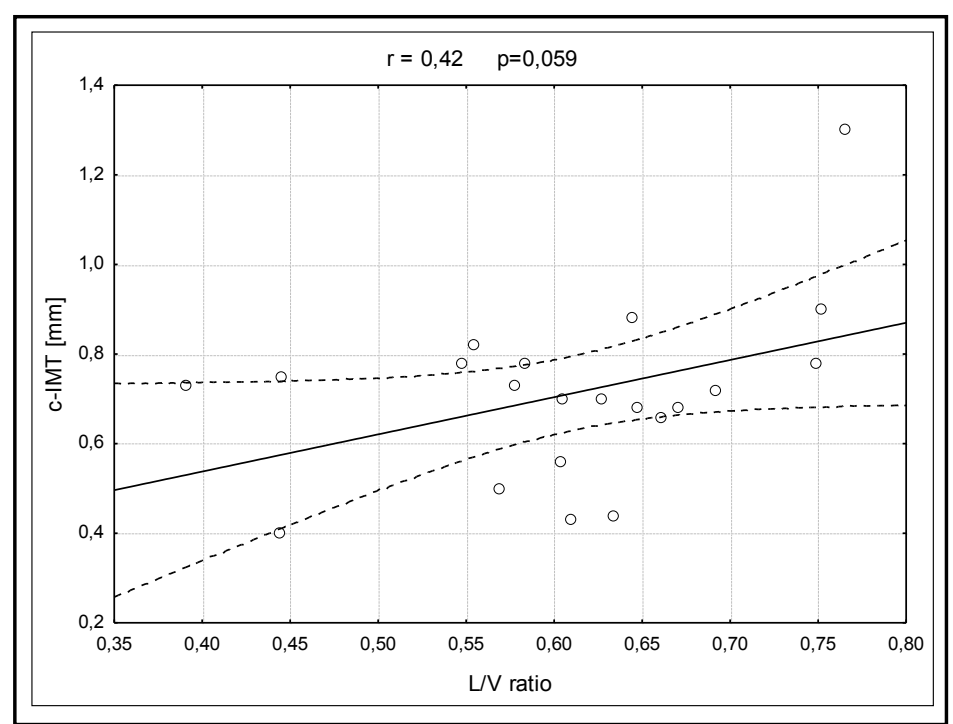

\section{Discussion}

The peritoneal network which connect the systemic vasculature and peritoneal cavity. This special network participates in numerous physiological conditions like solute and water transport, regulation of ultrafiltration, delivery of nutrients, hormones, leukocytes to inflammation areas. The peritoneal microcirculation consists of arterioles, capillaries and venules. Arterioles which range in diameter is from 5 to $100 \mu \mathrm{m}$ give rise directly to the metaarterioles $(10-20 \mu \mathrm{m}$ in diameter) and to capillaries $(5-10 \mu \mathrm{m}$ in diameter). Metaarterioles can bypass capillary circulation and serve as channels to venules $[12,13]$.

CKD patients present extremely high CV risk and high CV mortality and morbidity. It was widely shown in many studies that cardiovascular status at the beginning of dialysis greatly affects patients outcomes [5]. The population at extremely high risk are patients with diabetes.

The aim of our study was to assess peritoneal membrane arteriolar structure and perform global CV system status assessment using non-invasive methods in patients with advanced CKD just before initiation of PD with comparison of diabetic and non-diabetic population. The peritoneal microcirculation function and structure may be affected by many physiological and pathological conditions and specific processes related to peritoneal dialysis. The influence of age, hypertension, diabetes mellitus, subclinical inflammation and uremia per se had been reported [14]. Conventional high-glucose based fluids used in long-term PD treatment are responsible for aggravation of PM fibrosis and alterations in peritoneal microcircluation. Enhanced neoangiogenesis and progressive obliterative vasculopathy are common in PD patients $[15,16]$. Different degrees of vasculopathy with vessel wall thickening, hyaline material deposits and vessels lumen obliteration may be observed in PD pts but these processes are initiated in predialysis period.

In our study we did not find any statistically significant differences in peritoneal arteriolar indices i.e. peritoneal wall thickness (WT) and L/V ratio between diabetic and nondiabetic patients. There was only tendency to lower values of $\mathrm{L} / \mathrm{V}$ ratio in diabetic patients. It may indicate higher degree of arteriolar obliteration in this group. Peritoneal arteriolar wall thickness was greater in the analyzed diabetic patients (Table 2). Assessment of population with overt CAD or CHF and without ones show no differences in most of arteriolar indices except L/V ratio (statistically significant differences in population with and without CHF) (Table 4 and Table 5). It seems that arteriolar obliteration may be even worse in population without overt CHF. We found linear correlations between WT vs $\Delta \mathrm{P}(\mathrm{R}=-0,62 ; \mathrm{p}=0,02)$; WT vs $\Delta \mathrm{Hb}(\mathrm{R}=-0,54 ; \mathrm{p}=0,05)$ in non-diabetic group that may indicate the influence of calciumphosphorus metabolism derangements and renal anemia on arteriolar structure. The positive linear correlation between WT vs $\operatorname{DBP}(R=0,64 ; p=0,04)$ in diabetic subpopulation may indicate the influence of systemic hypertension on peritoneal arteriolar structure. 


\section{Kidney Blood Pressure Research}

Kidney Blood Press Res 2018;43:1042-1052

\begin{tabular}{l|l}
\hline DOI: $10.1159 / 000490827$ & C 2018 The Author(s). Published by S. Karger AG, Base
\end{tabular}

Published online: 25 June, 2018

www.karger.com/kb

1049

We suppose that uremia, hypertension and hyperglycemia affect both PM arteriolar and macrocirculation function and structure.

Ooi et al. analyzed microvasculature in CKD patients by measurements of retinal vessels diameter. They found smaller diameter of vessels of CKD stage 3-5 pts in compare to stage 1-2 pts but individuals with CKD stage 5 and diabetic patients had larger mean vessel diameter than non-diabetics. The authors concluded that the process of narrowing of microvasculature in CKD patients increases progressively with eGFR reduction [17]. Burkhardt et al. in their study wanted to assess the degree of "uremic microangiopathy" by means of measuring microvascular density in biopsies of the peritoneal omentum of 23 CKD stage 5 children. They proved that microvascular density was significantly reduced in omental biopsies and it was associated with diminished of angiopoetin 2 (Angpt2) signaling [18]. They introduced the term "uremic microangiopathy" into the terminology of small vessels disease in CKD patients. Capillary rarefaction was also documented in skeletal muscles and in myocardium of animals with experimental CKD [18]. Honda et al. in their study pointed out that average peritoneal membrane thickness and lumen/vessel diameter ratio were useful morphological parameters which may be adopted to qualify the severity of peritoneal alterations in uremic and PD patients. The lumen/vessel diameter ratio was lower in uremic patients than control and progressively decreased during PD [19]. Savidaki et al. compared alterations in peritoneal membrane in patients who had just started PD with those who completed 4 years period of CAPD. He found that structural changes (loss of mesothelial cells, thickening of submesothelial collagenous zone, vascular hyalinosis) were observed in the peritoneal membrane of uremic patients and those changes became worse after 4 years of CAPD treatment. In his study structural changes were not followed by functional changes (changes in peritoneal equilibration test-PET and dialysis adequacy) during the first 4 years of treatment [20]. Contreras-Velazquez in his study compared peritoneal histology of uremic diabetic and non-diabetic patients starting PD. As a control, he used non-diabetic, nonuremic patients who underwent non-complicated elective abdominal surgery. All peritoneal morphological changes were more emphasized in the diabetic group, and especially in this group, there was a higher proportion of vascular wall thickening/sclerosis than in nondiabetic individuals. The most important predictor of peritoneal vessel changes and clinical outcomes was diabetes (stronger than uremia per se) and hypoalbuminemia [21].

Besides arteriolar structure we analyzed heart structure and performed non-invasive large arteries assessment. We did not find any statistically significant difference in echocardiographic parameters between analyzed diabetic and non-diabetic population. In our opinion these results are related with good BP control and common use of ACE-I and sartans in treatment of hypertension in analyzed population before RRT initiation.

Another part of our investigation was assessment of c-IMT in all participants. Increased c-IMT complex is a well-known parameter which reflects early atherosclerotic lesions and indicate higher cardiovascular risk in patients with hypertension and also predict incident CKD in the general population [22]. There were not any statistically significant differences in c-IMT measurements in both analyzed groups (Table 2). We found linear correlation between c-IMT and arteriolar indices in population with overt CVD i.e positive correlation between c-IMT and L/V ratio and negative correlation between c-IMT and WT (Fig. 2 and Fig. 3). The simple explanation of these associations may be difficult. We have not find any similar association in other authors reports. Honda et al. in his study found positive correlation between WT and peritoneal thickness in uremic patients and PD patients and negative correlation between L/V ratio and PD duration [19]. We assume that there is relationship between arteriolar structural changes and large arteries changes. Previous studies in patients with CKD stage 1-5 found the tendency of c-IMT value to rise in subsequent groups of patients along with eGFR decrease $[1,23]$. Other authors did not find any differences between c-IMT values in analyzed groups of CKD predialysis patients, patients treated with hemodialysis and PD and control group [24]. It is worth to emphasize that assessment of c-IMT complex together with eGFR and proteinuria evaluation and presumably with arteriolar indices 


\section{Kidney Blood Pressure Research}

Kidney Blood Press Res 2018;43:1042-1052

\begin{tabular}{l|l}
\hline DOI: $10.1159 / 000490827$ & (C) 2018 The Author(s). Published by S. Karger AG, Basel
\end{tabular}

Published online: 25 June, 2018

www.karger.com/kb

1050

evaluation in CKD patients may be valuable diagnostic tool to detect population of increased CVD risk.

Moreover, in our study we performed PWV measurements in all analyzed patients. We found statistically significant higher PWV values in diabetic patients than in non-diabetic $(p=0,029)$ (Table 2). PWV which reflects arterial stiffness is willingly assessed by many investigators in different population of CKD patients such as predialysis, hemodialysis, PD and kidney transplant recipients. Stróżecki et al. found increased arterial stiffness in nondialyzed diabetic kidney disease patients. In this group PWV was significantly higher in compared with individuals without diabetes and control group. Moreover, these researchers found increased accumulation of advanced glycation end-products (AGEs) particularly in diabetic patients, but their results are not sufficient to confirm causal role of AGEs in arterial stiffening [25]. We found positive linear correlation between PWV and c-IMT (diabetic group) that may be a sign of global arteries derangements in CKD patients. We also found positive linear correlation between PWV and age which was confirmed by other authors (Table 3).

The important limitation of our study was the fact that we were unable to compare specimens of the peritoneal membrane with similar ones obtained from patients with earlier CKD stages (stage 2-4) and from patients on chronic PD treatment. Moreover, we are unable to refer our results to control group because the study design did not consider to make any comparison with normal peritoneal membrane. We were more interested to make a division into groups with and without diabetic kidney disease and perform comparison between them. We are aware that the accurate histopathological peritoneal membrane assessment is based on evaluation of not only peritoneal arteries or veins but depends on assessment of peritoneal thickness (thickness of submesothelial compact collagenous zone) or peritoneal vessels density. In our study we evaluate a small part of peritoneal microcirculation arteriolar morphology but it was our assumption to compare it with macrocirculation.

We suppose that arteriolar damage can be initiated at early stage of CKD, may progress with renal function decline and it may be parallel to macrocirculation damage. We suspect that arteriolar condition of peritoneal membrane seems to be worse in diabetic kidney disease in compare to non-diabetic patients. Further studies are necessary to prove these assumptions.

\section{Conclusion}

Peritoneal membrane arteriolar damage seems to be an integrated part of cardiovascular system damage in CKD stage 5 patients. The peritoneal membrane arteriolar structure changes seems to be increased in diabetic kidney disease patients. Further studies are required and non-invasive markers are necessary to evaluate function and structure of peritoneal microcirculation in advanced CKD before starting RRT.

\section{Abbreviations}

CKD (chronic kidney disease); PD (peritoneal dialysis); CAPD (continuous ambulatory peritoneal dialysis); APD (automated peritoneal dialysis); RRT (renal replacement therapy); CGN (chronic glomerulonephritis); CV (cardiovascular); CVD (cardiovascular disease); PWV (pulse wave velocity); IMT (intima media thickness); BMI (body mass index); BSA (body surface area); WHR (waist hip ratio); SBP (systolic blood pressure); DBP (diastolic blood pressure); ABPM (ambulatory blood pressure monitoring); PP (pulse pressure); MAP (mean arterial pressure); eGFR (estimated glomerular filtration rate); Hgb (hemoglobin); SA (serum albumin); CRP (C reactive protein); TCH (total cholesterol); TSAT (transferrin saturation); PTH (parathormone); IVSd (intraventricular septum thickness in end-diastole); LVIDd (left ventricular internal dimension in end-diastole); PWd (posterior wall in end diastole); EF 


\section{Kidney \\ Blood Pressure Research}

Kidney Blood Press Res 2018;43:1042-1052

\begin{tabular}{l|l}
\hline DOI: $10.1159 / 000490827$ & (C) 2018 The Author(s). Published by S. Karger AG, Basel
\end{tabular}

Published online: 25 June, 2018

www.karger.com/kb

1051

(ejection fraction); LVM (left ventricular mass); LVH (left ventricular hypertrophy); RWT (left ventricule relative wall thickness); LVMI (left ventricular mass index); c-IMT (carotid intima-media thickness); WT (wall thickness); L/V (peritoneal vessel lumen/ peritoneal vessel diameter ratio); AGEs (advanced glycation end-products); VEGF (vascular endothelial growth factor); Angpt1 (angiopoietin 1); Angpt2 (angiopoetin 2); CKD-MBD (Chronic kidney disease - mineral and bone disorder); RRF (residual renal function); PET (peritoneal equilibration test); KDIGO (Kidney Disease Improving Global Outcomes); CAD (coronary artery disease); CHF (congestive heart failure); TIA (transient ischemic attack); ACE-Is (angiotensin converting enzyme inhibitors); ARBs (angiotensin receptor blockers); SD (standard deviation); IQR (interquartile range).

\section{Acknowledgements}

All the authors of this work have read and approved the final version of the manuscript. We want to thank all our patients and their families for their invaluable cooperation during the study. Special thanks for Mr. Paweł Gontarek for his precious technical support during histopathological evaluation.

RD, JM and PS proposed the concept of the study. RD, MG, BS, RT recruited the patients. MB, AM prepared histopathological evaluation. JS, AS, GOS performed all biochemical tests. RD, PS, JM prepared the manuscript. PS, RD revised statistical analysis of the study.

All data related to this article are shown in the manuscript or available upon request from the corresponding author.

This paper was supported by Nicolaus Copernicus University in Torun Rector's grant No 03/CM and was partially financed from the "NERKADAR" foundation at Department of Nephrology, Hypertension and Internal Medicine in Bydgoszcz.

\section{Disclosure Statement}

The authors declare that they have no competing interests.

\section{References}

1 Pluta A, Stróżecki P, Krintus M, Odrowąż-Sypniewska G, Manitius J: Left ventricular remodelling and arterial remodelling in patients with chronic kidney disease stage 1-3. Ren Fail 2015;37:1105-1110.

2 Longenecker JC, Coresh J, Powe N, Levey A, Fink N, Martin A, Klag M: Traditional Cardiovascular Disease Risk Factors in Dialysis Patients Compared with the General Population: The CHOICE Study. J Am Soc Nephrol 2002;13:1918-1927.

-3 Lai S, Dimko, Galani A, Coppola B; Innico G, Frassetti N, Mazzei ED, Mariotti A: Early markers of cardiovascular risk in chronic kidney disease. Ren Fail 2015;37:254-261.

4 Sun W, Liu D, Gong P, Shi X, Wang Y, Wang P, Gong W: Predicting cardiovascular mortality in chronic kidney disease (CKD) patients. Ann Transplant 2014;19:513-518.

5 Locatelli F, Pozzoni P, Tentori F, Vecchio L: Epidemiology of cardiovascular risk in patients with chronic kidney disease. Nephrol Dial Transplant 2003,18:vii2-vii9.

6 Goicoechea M, Garcia de Vinuesa S, Gomez-Campdera F, Luno J: Predictive cardiovascular risk factors in patients with chronic kidney disease (CKD). Kidney Int Suppl 2005;67:S35-S38.

7 Kalantar-Zahed K, Block G, Humphreys MH, Kopple JD: Reverse epidemiology of cardiovascular risk factors in maintenance dialysis patients. Kidney Int 2003;63:793-808.

8 Fontana F, Ballestri M, Makomi C, Morandi R, Cappelli G: Hemorheologic alterations in peritoneal dialysis. Clin Hemorheol Microcirc 2017;65:175-183. 


\section{Kidney \\ Blood Pressure Research}

Kidney Blood Press Res 2018;43:1042-1052

\begin{tabular}{l|l}
\hline DOI: $10.1159 / 000490827$ & (C) 2018 The Author(s). Published by S. Karger AG, Basel
\end{tabular}

Published online: 25 June, 2018 www.karger.com $/ \mathrm{kbr}$

-9 Gillerot G, Goffin E, Michel C, Evenepoel P, van Biesen W, Tintillier M, Stenvinkel P, Heimburger O, Lindholm B, Nordfors L, Robert A, Devuyst O: Genetic and clinical factors influence the baseline permeability of the peritoneal membrane. Kidney Int 2005;67:2477-2487.

10 Kawanishi K, Honda K, Tsukada M, Oda H, Nitta K: Neutral solution low in glucose degradation products is associated with less peritoneal fibrosis and vascular sclerosis in patients receiving PD. Perit Dial Int 2012;1:573-580.

11 Devuyst 0, Topley N, Williams J: Morphological and functional changes in the dialyzed peritoneal cavity: impact of more biocompatible solutions. Nephrol Dial Transplant 2002;17:12-15.

12 De Vriese AS, White R, Graner DN, Lameire NH: The peritoneal microcirculation in peritoneal dialysis; in Khanna R and Krediet RT (eds): Nolph and Gokal's Texbook of Peritoneal Dialysis, ed 3. Springer US, 2009, pp 51-71.

13 Rippe B, Rosengren BI, Venturoli D: The peritoneal microcirculation in peritoneal dialysis . Microcirculation 2001;8:303-320.

14 Lameire N, Mortier S, De Vriese AS: Peritoneal microcirculation; in: Ronco C, Dell'Aquila R, Rodighiero MP (eds): Peritoneal Dialysis Today.Contrib Nephrol. Basel, Karger, 2003, vol 140, pp 56-69.

15 Williams JD, Craig KJ, Topley N, Von Ruhland C, Fallon M, Newman GR, Mackenzie RK, Willimas GT:Peritoneal Biopsy Study Group: Morphologic changes in peritoneal membrane of patients with renal disease. J Am Soc Nephrol 2002;13:470-479.

16 Vlijm A, Sampimon DE, de Graaff M, Struijk DG, Krediet RT: A two-hit approach in the development of an experimental peritoneal sclerosis model. Adv Perit Dial 2012;28:26-31.

17 Ooi QL,Tow FK, Deva R, Alias MA, Kawasaki R, Wong TY, Mohamad N, Colville D, Hutchinson A, Savige J: The Microvasculature in Chronic Kidney Disease. Clin J Am Soc Nephrol 2011;6:1872-1878.

18 Burkhardt D, Bartosova M, Schaefer B, Grabe N, Lahrmann B, Nasser H, Freise C, Schneider A, Lingnau A, Degenhardt P, Ranchin B, Sallay P, Cerkauskiene R, Malina M, Ariceta G, Schmitt CP, Querfeld U: Reduced Microvascular Density in Omental Biopsies of Children with Chronic Kidney Disease. PLoS One 2016;11:e0166050.

19 Honda K, Hamada C, Nakayama M, Miyazaki M, Sherif AM, Harada T, Hirano H: Impact of uremia, diabetes and peritoneal dialysis itself on the pathogenesis of peritoneal sclerosis: a quantitative study of peritoneal membrane morphology. Clin J Am Soc Nephrol 2008;3:720-728.

20 Savidaki I, Karavias D, Sotsiou F, Alexandri S, Kalliakmani P, Presvelous D, Papachristou E, Goumenos DS, Vlachojannis JG: Histologic change of peritoneal membrane in relation to adequacy of dialysis in continuous ambulatory peritoneal dialysis patients. Perit Dial Int 2003;23:26-30.

21 Contreras-Velazquez JC, Soto V, Jaramillo-Rodriguez Y, Samaniego-Rios LI, Quinones-Peres V, Avila M, Amato D, Paniagua R: Clinical outcomes and peritoneal histology in patients starting peritoneal dialysis are related to diabetic status and serum albumin levels. Kidney Int 2008;73:34-41.

-22 Takenouchi A, Tsuboi A, Kurata M, Fukuo K, Kazumi T: Carotid intima-media thickness and visit-to-visit HbA1c variability predict progression of chronic kidney disease in type 2 diabetic patients with preserved kidney function. J Diabetes Res 2016;5:1-6.

-23 Zhang L, Zhao F, Yang Y, Qi LT, Zhang BW, Wang F, Wang SY, Liu LS: Association between carotid artery intima-media thickness and early stage CKD in a Chinese population. Am J Kidney Dis 2007;49:786-792.

24 Konings CJ, Dammers R, Rensma PL, Kooman JP, Hoeks AP, Kornet L, Gladziwa U, van der Sande FM, Leunissen KM: Arterial wall properties in patients with renal failure. Am J Kidney Dis 2002;39:1206-1212.

-25 Stróżecki P, Kurowski R, Flisiński M, Stefańska A, Odrowąż-Sypniewska G, Manitius J: Advanced glycation end-products and arterial stiffness in patients with diabetic nephropathy and patients with chronic kidney disease without diabetes: Pol Arch Internal Med 2013;123:609-615. 